\title{
CONSUMER ACCEPTABILITY STUDIES IN SHELF-LIFE ESTIMATION OF RAPESEED AND SUNFLOWER OILS
}

\author{
U. SАMOTYJA* \\ Poznań University of Economics, al. Niepodległości 10, 61-875 Poznań. Poland
}

(Submitted: 30 May 2013; accepted: 14 June 2013)

\begin{abstract}
Shelf-life of plant oils is determined by oxidative stability. The consumers use their own criterion to assess oil's quality. The occurrence of perceptible changes in oxidized food provides information that the product is no longer safe and should not be accepted. The present study was aimed to determine the shelf-life of rapeseed and sunflower oils in terms of consumer acceptance. The results of sensory consumer acceptability tests followed by survival analysis were integrated with conventional chemical marker of oils' quality and shelf-life (peroxide value).

The important finding is that consumers sometimes do not recognize the advanced oxidative processes in food. This may increase the safety risk because of the harmful effect of oxidative processes on human health. Consumers differentiated quality of oils with similar state of oxidation: the rapeseed oil with peroxide value on the level 5 meq $\mathrm{O}_{2} \mathrm{~kg}^{-1}$ was rejected by three quarters of consumers, sunflower - by only $3 \%$. It proves that the consumer perception of oxidative changes is specific to the product and does not coincide with the accepted chemical criterion of shelf-life.
\end{abstract} oxidation

Keywords: food safety and nutrition, shelf-life, consumer issues, consumer acceptability, survival analysis,

'Shelf-life' is defined as 'the time during which the product remains safe, retains desired sensory, chemical, physical, and microbiological characteristics, and complies with any label declaration of nutritional data, when stored under the recommended conditions' (IFST, 1993). Some authors emphasize the consumer perception of a product and define 'shelf-life' as the time beyond which the product is no more acceptable (Fu \& LABUZA, 1993, HougH et al., 2006b). The final verification is always made by a consumer who accepts the product or does not on the basis of sensory perception. Lack of sensory acceptance is the most common reason of consumer rejection (Hough, 2010).

Considering shelf-life as a food-consumer interaction, one should focus on consumer attitude towards quality changes and a consumer rejecting a product (Hough et al., 2006b). Survival analysis is being used to determine the probability, that after a given time the product will no longer be accepted. Assignation of time, in which the probability does not exceed the assumed value, is equivalent to shelf-life determination. Survival analysis, initially used in biological, medical, socio-economic sciences, and engineering, was proposed in shelf-life studies (GACULA \& KUBALA, 1975) and later used by other authors to study the consumer attitude during storage of yoghurts (CuRIA et al., 2005), raw minced beef (Hough et al., 2006a), Fuji apples (VArela et al., 2005), minimally processed lettuce (Ares et al., 2008), and so on. An interesting approach was presented by MAnzocco and LAGAZIo (2009) - the consumer acceptability data were integrated with changes in quality indices during storage of coffee brew.

\footnotetext{
* To whom correspondence should be addressed

Phone: + 48-61-856-9035; fax: +48-61-854-3993; e-mail: u.samotyja@ue.poznan.pl
} 
Plant oils are specific products, whose quality is determined first of all by oxidative stability. Their shelf-life is limited by the oxidative changes, which can be detected with the use of one of the analytical methods measuring the level of oxidation products or the lack of some compounds (KOZAK \& SAMOTYJA, 2013). The consumer will use his own criterion for oil's quality assessment. At more advanced stages of oxidation the primary products (hydroperoxides) decompose and secondary compounds with low odour threshold are formed (Min \& Boff, 2002). There is little knowledge on consumer awareness regarding oxidative changes in foods. Calligaris and co-workers (2008) measured the oxidative stability of breadsticks and the results were related to the sensory acceptance limit. Surprising results were obtained by RAMIREZ and co-workers (2001) - some consumers prefer the more oxidized oil samples than the fresh ones. Consumers can achieve the established benefits of regular consumption of food containing unsaturated fatty acids (ŠKRBIĆ \& MAČVANIN, 2011) but without awareness of quality it is not possible. The questions still to be answered are: (i) do consumers notice the oxidative changes in plant oils? (ii) is the sensory shelf-life perceived in the same way in case of oils with different profile of fatty acids? (iii) what is the critical limit of hydroperoxides from consumer rejection point of view?

The aim of the present study was to determine the shelf-life of rapeseed and sunflower oils with the use of sensory consumer acceptability tests.

\section{Materials and methods}

The subjects of investigation were commercially available refined oils: rapeseed and sunflower, sold in $1000 \mathrm{ml}$ PET bottles. After opening, the samples of the same kind were blended to minimize the variations between batches. The characteristics of the samples are provided in Table 1. The initial peroxide value was determined as described below, acid value according to ISO (2009).

Fatty acid methyl esters were obtained according to method of SCHULTE and WEBER (1989) and analyzed with the use of gas chromatograph Varian 3800 equipped with a FID detector with the use of BPX-70 column (SGE, $60 \mathrm{~m} \times 0.25 \mathrm{~mm}, 0.25 \mu \mathrm{m}$ film thickness).

Table 1. Characteristics of rapeseed and sunflower oils

\begin{tabular}{lcc}
\hline & Rapeseed oil & Sunflower oil \\
\hline $\mathrm{PV}\left(\mathrm{meq} \mathrm{O}_{2} \mathrm{~kg}^{-1}\right)$ & $0.6 \pm 0.1$ & $2.0 \pm 0.3$ \\
Acid value $\left(\mathrm{mg} \mathrm{KOH} \mathrm{g}^{-1}\right)$ & $0.10 \pm 0.01$ & $0.19 \pm 0.02$ \\
Predominant fatty acids (\%) & & \\
$\mathrm{C} 16: 0$ & $4.5 \pm 0.2$ & $5.9 \pm 0.0$ \\
$\mathrm{C} 18: 0$ & $1.8 \pm 0.0$ & $4.2 \pm 0.1$ \\
$\mathrm{C} 18: 1$ & $63.0 \pm 0.1$ & $23.8 \pm 0.2$ \\
$\mathrm{C} 8: 2$ & $17.7 \pm 0.2$ & $65.6 \pm 0.4$ \\
$\mathrm{C} 8: 3$ & $8.9 \pm 0.1$ & n.d. ${ }^{1}$ \\
\hline 1 n.d: Not detected & &
\end{tabular}


Equal volumes of oils $(250 \mathrm{ml})$ were placed in closed $500 \mathrm{ml}$ containers and stored at $50{ }^{\circ} \mathrm{C}$ in the dark. It was assumed that elevated temperature accelerates autoxidation reducing the duration of experiment without any influence on the mechanism of oxidative deterioration (FrANKEL, 1998). It was possible to observe the same direction of changes that would occur during practical storage and product usage by a consumer.

\subsection{The experiment design}

In shelf-life studies of food products samples with different storage times are presented to consumers. The reversed storage design was applied to have all samples with different storage times available on the same day (KILCAST \& SUBRAmAniam, 2000). There was only one starting point for all the samples. The samples were withdrawn after 2, 3, 4, 6, 8, and 10 days of storage and kept at $-18{ }^{\circ} \mathrm{C}$ till evaluation. The samples from the beginning of the experiment (day 0) were also frozen. After the end of the storage period the samples were defrosted and the analyses of hydroperoxides and sensory acceptability tests were conducted.

\subsection{Hydroperoxides measurements}

Hydroperoxides content in rapeseed and sunflower oils were measured according to EN ISO (2010), where a method for the iodometric (visual) determination of the peroxide value is given. The results were expressed as peroxide value in meq $\mathrm{O}_{2} \mathrm{~kg}^{-1}$.

\subsection{Consumer test}

The study was carried out with 90 consumers who usually consumed or used plant oils. The samples were assessed for their odour properties in a sensory laboratory.

Thirty $\mathrm{ml}$ portions of the samples, after reaching a final temperature of $20{ }^{\circ} \mathrm{C}$ were placed in $150 \mathrm{ml}$ glass amber bottles and capped to permit volatiles to build in the headspace. Glass beads were used to enhance the release of odour volatiles when the sample is swirled prior to sniffing (MALCOLMSON, 2005). The consumers obtained the coded tray with 7 samples corresponding to the following scheme: 0-2-3-4-6-8-10 days, separately for rapeseed and sunflower oils, presented in random order and labelled with three-digit random numbers. They were asked to sniff the sample, evaluate the rancid odour and answer 'yes' or 'no' to the question: 'Imagine that you have this oil stored in your kitchen, would you normally consume it?' It was assumed that the product is in the consumer's house, as ARES and co-workers (2008) noticed that estimated shelf-life vary depending on that consumers are deciding whether to purchase or to consume a food product. Shelf-lives estimated considering rejection to purchase were significantly shorter than those estimated considering rejection to consume. When evaluating attitude during usage at home it was reasonable to assess the consumers' rejection to consume after purchase.

\subsection{Statistical analysis}

Survival analysis methodology was used to estimate the shelf-life of oil samples using the results obtained from the sensory test. Defining a random variable $\mathrm{T}$ as the storage time beyond which consumer rejects the sample, the survival function $S(t)$ was estimated as the probability of a consumer accepting a product stored beyond time $t$, that is $S(t)=P(T>t)$ (Gacula \& Singh, 1984). The Weibull distribution was applied to model rejection times. The Statistica PL 10.0 software was used to calculate the survival data (Statsoft, Poland). 


\section{Results and discussion}

The hydroperoxide formation during the storage of the samples is presented in Fig. 1. The hydroperoxide content increased during storage and was higher in the sunflower oil during the entire time of the experiment. According to Polish Standard (2000), the limiting level of peroxide value in refined oils is 5 meq $\mathrm{O}_{2} \mathrm{~kg}^{-1}$. It was exceeded after 7.3 (rapeseed oil) and 3.6 (sunflower oil) days of storage showing 2 -fold longer shelf-life of rapeseed oil.

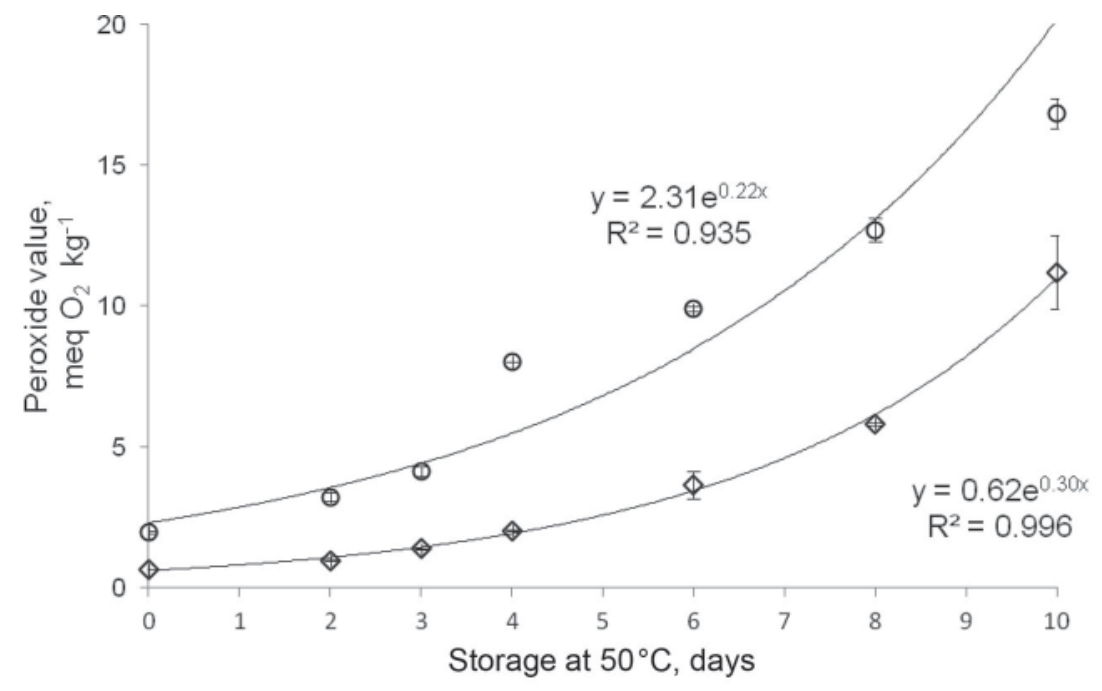

Fig. 1. The influence of storage time at $50^{\circ} \mathrm{C}$ on oxidation of rapeseed and sunflower oils. $\diamond$ : rapeseed oil; $\circ$ : sunflower oil

Figures 2 and 3 show the estimated \% of acceptability versus time. Presented curves are called survival function, acceptability function or, related to the present study, the shelf-life curves and show the probability of acceptance loss during storage. The decrease of acceptance during storage is unequivocal with the increasing risk of rejection. The loss of acceptance occurred faster in case of rapeseed (Fig. 2) than sunflower oil (Fig. 3). The results of the present work show that when the peroxide value in rapeseed oil exceeded the critical level of 5 meq $\mathrm{O}_{2} \mathrm{~kg}^{-1}$ (eighth day), only a quarter of the consumers still accepted the product. In other words, three quarters of consumers rejected the product before the critical limit of hydroperoxides was achieved. Diverse consumers' attitude was observed toward sunflower oil - when the critical level of hydroperoxide was exceeded (fourth day), $97 \%$ of consumers still accepted the product, meaning that until this time the risk of rejection was only $3 \%$.

The estimated shelf-life of oils was expressed as the time in which the probability of rejection would not exceed the established value and is presented in Table 2, together with $95 \%$ confidence intervals. The probability level established for shelf-life estimation purpose is the value of the conventional (Hough et al., 2006b). Usually shelf-life is estimated based on $25 \%$ and $50 \%$ percentiles and such values are presented in this study. Due to the software, these values can be easily computed and read from the shelf-life loss table. The selection of 
the proper probability of a consumer rejection is important for economic reasons - longer shelf-life declared would increase the competitiveness of the brand and may give a better chance that the product is sold minimising the loss of retailer. Unfortunately, on the other hand, it carries the risk of diminished consumer confidence in the brand, increased number of complaints, and consequently, the loss of reputation leading to not purchasing that brand again. Therefore, it is essential for the manufacturing companies to find the proper balance.

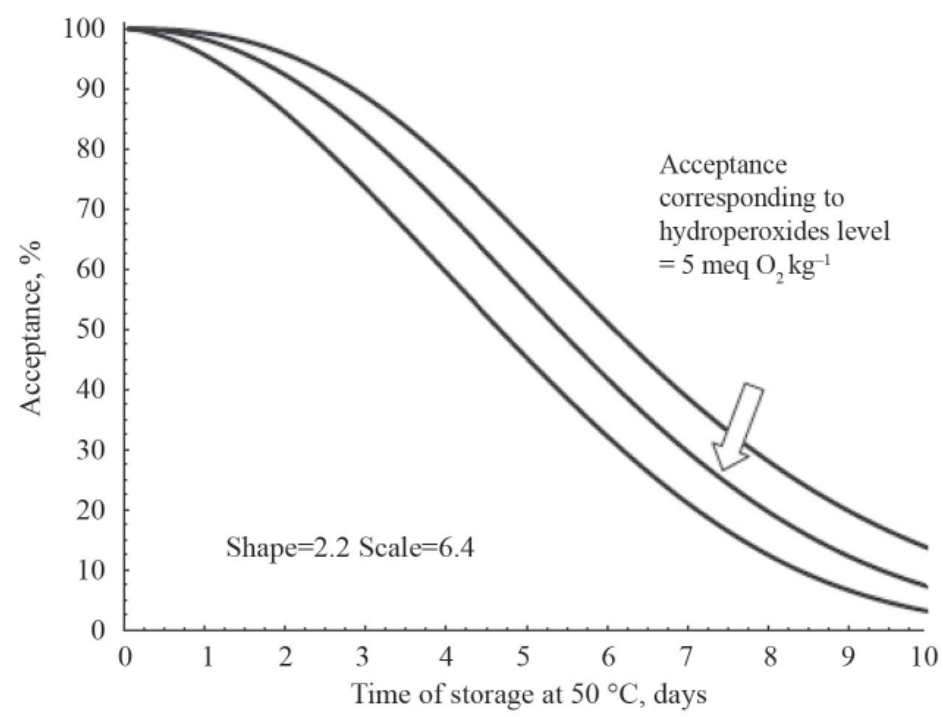

Fig. 2. Percentage of consumers accepting the rapeseed oil vs. time of storage at $50{ }^{\circ} \mathrm{C}$ (confidence bands at $95 \%$ )

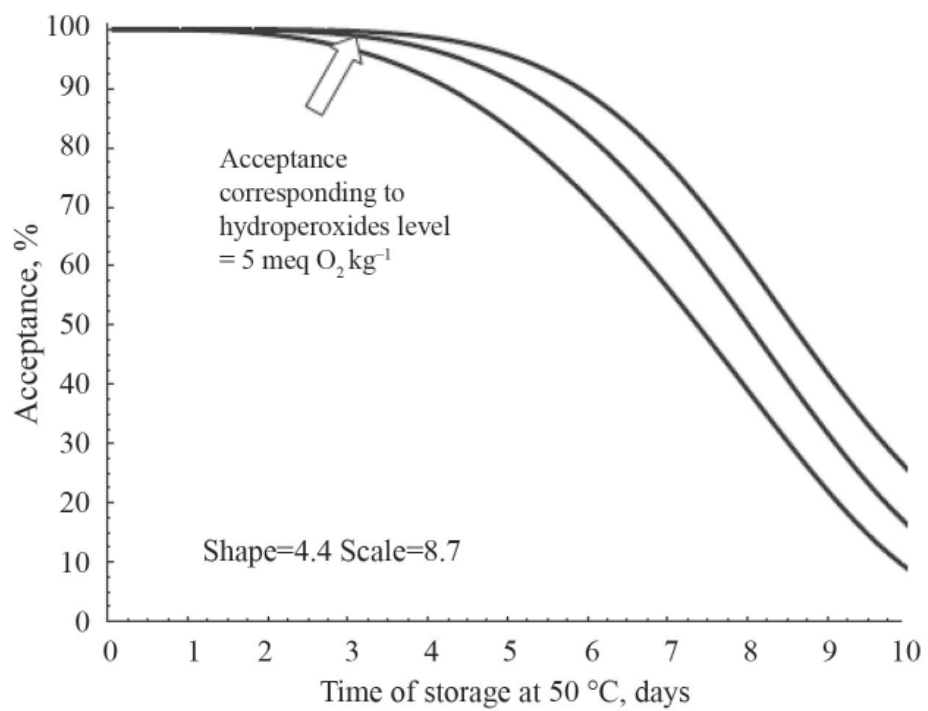

Fig. 3. Percentage of consumers accepting the sunflower oil vs. time of storage at $50{ }^{\circ} \mathrm{C}$ (confidence bands at $95 \%$ ) 
Table 2. Shelf-life values estimated for $25 \%$ and $50 \%$ probability of consumers' rejection

\begin{tabular}{|c|c|c|c|c|c|c|}
\hline \multirow{2}{*}{$\begin{array}{l}\text { Probability of } \\
\text { rejection }(\%)\end{array}$} & \multicolumn{3}{|c|}{ Rapeseed oil } & \multicolumn{3}{|c|}{ Sunflower oil } \\
\hline & $\begin{array}{c}\text { Shelf life at } \\
50^{\circ} \mathrm{C} \\
\text { (days) }\end{array}$ & $\begin{array}{c}\text { Lower } \\
\text { confidence } \\
\text { limit (days) }\end{array}$ & $\begin{array}{c}\text { Upper } \\
\text { confidence } \\
\text { limit (days) }\end{array}$ & $\begin{array}{c}\text { Shelf life at } \\
50^{\circ} \mathrm{C} \\
\text { (days) }\end{array}$ & $\begin{array}{c}\text { Lower } \\
\text { confidence } \\
\text { limit (days) }\end{array}$ & $\begin{array}{c}\text { Upper } \\
\text { confidence } \\
\text { limit (days) }\end{array}$ \\
\hline 25 & 3.6 & 3.0 & 4.4 & 6.7 & 6.0 & 7.4 \\
\hline 50 & 5.4 & 4.7 & 6.1 & 8.1 & 7.6 & 8.7 \\
\hline
\end{tabular}

With any level of the established probability, the rejection of sunflower oil would appear not only later than the rejection of rapeseed oil but also with higher peroxide value (Fig. 4). The corresponding peroxide value for $50 \%$ acceptation (equal to $50 \%$ rejection) of rapeseed and sunflower oil is about 3.2 meq $\mathrm{O}_{2} \mathrm{~kg}^{-1}$ and 10.5 meq $\mathrm{O}_{2} \mathrm{~kg}^{-1}$, respectively. Different consumer perception of oxidative changes in the two oils can be explained by the differences in their fatty acids profiles, influencing the quantity and the kind of the volatiles, their threshold values as well as the matrix effect (Min \& Boff, 2002; Kolb \& EtTre, 2006).

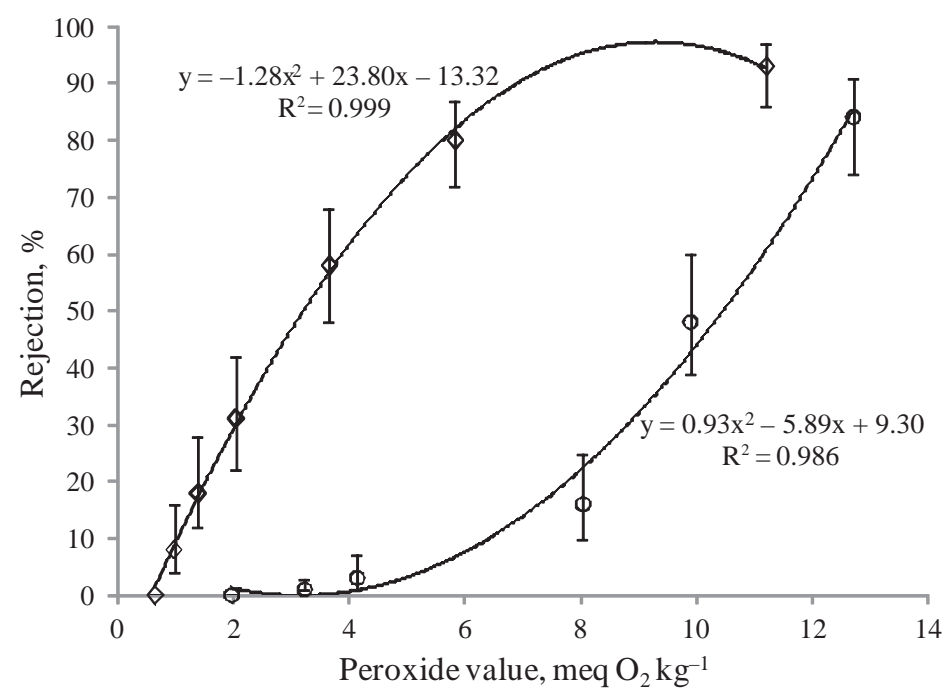

Fig. 4. Relationship between the extent of oxidation and consumers' rejection in rapeseed and sunflower oils. $\diamond$ : rapeseed oil; ○: sunflower oil

Development of sensory shelf-life model for a real product, stored or used under actual conditions by a defined group of consumers can be useful in shelf-life prediction. Due to the proposed way to integrate the sensory shelf-life with a chemical marker of quality, it is possible to replace consumer studies in shelf-life estimation with analytical procedures much simpler to conduct. It can also be a useful tool for shelf-life prediction when the storage temperature of the product is not known or it was not stable because it allows to relate chemical measure of quality to consumer acceptability without referring to the storage conditions. 


\section{Conclusions}

Although oil rejection is related to oxidative changes, the consumer perception of quality deterioration is specific to the product and does not coincide with the limiting value of conventional measure of shelf-life. The rapeseed oil was rejected at the early stage of oxidation; contradictory, sunflower oil was still accepted despite exceeding the critical hydroperoxide content. There is a risk that consumers would not recognize the advanced processes in food. Because of potential consequences, the issues of consumers' perception of shelf-life should be relevant both for consumers and manufacturing companies.

The author is grateful to Mrs P. Pacholak and Mr. K. Grabowski for providing technical assistance.

\section{References}

Ares, G., Gimenez, A. \& Gambaro, A. (2008): Sensory shelf-life estimation of minimally processed lettuce considering two stages of consumers' decision-making process. Appetite, 50, 529-535.

Calligaris, S., Pieve, S.D., Kravina, G., Manzocco, L. \& Nicoli, C.M. (2008): Shelf life prediction of bread sticks using oxidation indices: a validation study. J. Food Sci., 2, 51-56.

Curia, A., Aguerrido, M., Langohr, K. \& Hough, G. (2005): Survival analysis applied to sensory shelf-life of yogurts - I: Argentine formulations. J. Food Sci., 7, 442-445.

EN ISO (2010): Animal and vegetable fats and oils. Determination of peroxide value. Iodometric (visual) endpoint determination. No. 3960.

Frankel, E.N. (1998): Lipid oxidation. The Oily Press Ltd., Dundee, Scotland, pp. 99-114.

Fu, B. \& Labuza, T. (1993): Shelf-life prediction: Theory and application; Food Control., 4, 125-133.

Gacula, M.C. \& Kubala, J.J. (1975): Statistical models for shelf-life failure. J. Food Sci., 40, 404-409.

Gacula, M.C. \& Singh, J. (1984): Statistical methods in food and consumer research. Academic Press, New York, USA, pp. 274-312.

Hough, G., Garitta, L. \& Gómez, G. (2006a): Sensory shelf-life predictions by survival analysis accelerated storage models. Food Qual. Prefer., 17, 468-473.

Hough, G., Van Hout, D. \& KILcast, D. (2006b): Workshop summary: Sensory shelf-life testing. Food Qual. Prefer., 17, 640-645.

Hough, G. (2010): Sensory shelf-life estimation of food products. CRC Press, Boca Raton, USA, pp. 1-21, 83-112.

IFST (1993): Shelf-life of foods - guidelines for its determination and prediction. Institute of Food Science and Technology, London. 78 pages.

ISO (2009): Animal and vegetable fats and oils - Determination of acid value and acidity. No. 660.

Kilcast, D. \& Subramaniam, P. (2000): Introduction. -in: Kilcast, D. \& Subramaniam, P. (Eds), The stability and shelf-life of food. Woodhead Publishing Ltd, Cambridge, England, pp. 1-22.

Kolb, B. \& EtTre, L.S. (2006): Static headspace-gas chromatography: Theory and practice. John Wiley \& Sons, Inc, Hoboken, NJ, USA, pp. 221-226.

Kozak, W. \& SAmotyja, U. (2013): The use of oxygen content determination method based on fluorescence quenching for rapeseed oil shelf-life assessment. Food Control, 33, 162-165.

Malcolmson, L. (2005): Flavor and sensory aspects. -in: Shahidi, F. (Ed.): Bailey's industrial oil and fat products, $6^{\text {th }}$ ed, Six Volume Set. John Wiley \& Sons, Inc., pp. 413-429.

Manzocco, L. \& Lagazio, C. (2009): Coffee brew shelf-life modeling by integration of acceptability and quality data. Food Qual. Prefer., 20, 24-29.

Min, D.B. \& Boff, J.M. (2002): Lipid oxidation of edible oil. -in: Aкон, C.C. \& Min, D.B. (Eds) Food lipids. Marcel Dekker Inc., New York, Basel, pp. 335-411.

POLISH STANDARD (2000): Oleje i ttuszcze roślinne oraz zwierzęce-Rafinowane oleje roślinne (Animal and vegetable fats and oils - Refined plant oils.) No. PN-A-86908:2000.

Ramirez, G., Hough, G. \& Contarini, A. (2001): Influence of temperature and light exposure on sensory shelf-life of a commercial sunflower oil. J. Food Qualit., 24, 195-204.

Acta Alimentaria 44, 2015 
Schulte, E. \& Weber, K. (1989): Rapid preparation of fatty acid methyl esters from fats with trimethylsulfonium hydroxide or sodium methylate. Fat Sci. Technol., 91, 181-183.

ŠKrbić, B. \& MaČVAnin, N. (2011): Nutritional and sensorial aspects of wheat bread enriched with high-oleic sunflower seed. Acta Alimentaria, 40, 194-204.

Varela, P., Salvador, A. \& Fiszman, S. (2005): Shelf-life estimation of "Fuji" apples: Sensory characteristics and consumer acceptability. Postharvest Biol. Tech., 38, 18-24. 